UNU-WIDER

World Institute for Develepment

Economics Research

Research Paper No. 2008/107

\title{
Inequality and the Impact of Growth on Poverty: Comparative Evidence for Sub-Saharan Africa
}

\author{
Augustin Kwasi Fosu*
}

December 2008

\begin{abstract}
This study explores the extent to which inequality affects the impact of income growth on the rates of poverty changes in sub-Saharan Africa (SSA) comparatively with nonSSA, based on a global sample of 1977-2004 unbalanced panel data. For both regions and all three measures of poverty-headcount, gap, and squared gap - the paper finds the impact of GDP growth on poverty reduction as a decreasing function of initial inequality. The impacts are similar in direction for SSA and non-SSA, so that within both regions there are considerable disparities in the responsiveness of poverty to income growth, depending on inequality. Nevertheless, the income-growth elasticity is substantially less for SSA, implying relatively small poverty-reduction sensitiveness to growth compared with the rest of the developing world. Furthermore, the paper finds a considerable variation in the predicted values of the income-growth elasticity across a large number of SSA countries, implying the need for understanding country-specific inequality attributes for effective poverty-reduction strategies.
\end{abstract}

Key words: inequality, income growth, poverty, sub-Saharan Africa

JEL classification: D31, I32, O49

\section{Copyright (C) UNU-WIDER 2008}

*Deputy Director, UN University-World Institute for Development Economics Research (UNU-WIDER), Helsinki, Finland, email: Fosu@wider.unu.edu, and honorary RDRC Research Fellow, University of California, Berkeley, USA

This study has been prepared within the UNU-WIDER project on African Development: Myths and Realities, directed by Augustin K. Fosu.

UNU-WIDER gratefully acknowledges the financial contributions to the research programme by the governments of Denmark (Royal Ministry of Foreign Affairs), Finland (Ministry for Foreign Affairs), Norway (Royal Ministry of Foreign Affairs), Sweden (Swedish International Development Cooperation Agency_-Sida) and the United Kingdom (Department for International Development). 


\section{Acknowledgements}

The author is grateful to Jan-Erik Antipin for valuable research assistance and to the JDS editor, Oliver Morrissey, and two anonymous referees for helpful comments.

A version of this paper is accepted for publication in the Journal of Development Studies.

The World Institute for Development Economics Research (WIDER) was established by the United Nations University (UNU) as its first research and training centre and started work in Helsinki, Finland in 1985. The Institute undertakes applied research and policy analysis on structural changes affecting the developing and transitional economies, provides a forum for the advocacy of policies leading to robust, equitable and environmentally sustainable growth, and promotes capacity strengthening and training in the field of economic and social policy making. Work is carried out by staff researchers and visiting scholars in Helsinki and through networks of collaborating scholars and institutions around the world.

www.wider.unu.edu publications@wider.unu.edu

UNU World Institute for Development Economics Research (UNU-WIDER)

Katajanokanlaituri 6 B, 00160 Helsinki, Finland

Typescript prepared by Lisa Winkler at UNU-WIDER

The views expressed in this publication are those of the author(s). Publication does not imply endorsement by the Institute or the United Nations University, nor by the programme/project sponsors, of any of the views expressed. 


\section{Introduction}

Poverty has increasingly become an issue of major global interest, with halving extreme poverty by 2015 constituting the first, and perhaps the most critical, goal among the Millennium Development Goals (MDGs). Since the 1980s, the poverty rate has been trending significantly downward in all regions of the world except in sub-Saharan Africa (SSA), where Goal 1 seems unlikely to be achieved. Indeed, the poverty headcount ratio in SSA, measured as the proportion of the population living on less than US\$1 per day, rose slightly from 45 per cent in 1990 to 46 per cent in 2000 (World Bank 2006a), the year of the Millennium Declaration. Over the last quarter century, this headcount poverty rate has barely budged in SSA, from its value of 42 per cent in 1981 to 41 per cent most recently in 2004 (World Bank 2007). Meanwhile, a number of studies find that inequality plays an important role in the income-growth-poverty relationship (e.g., Adams 2004; Bourguignon 2003; Easterly 2000; Epaulard 2003; Fosu 2007; Kalwij and Verschoor 2007; Ravallion 1997). Thus, meeting the poverty targets of the MDGs, for instance, may require special attention predicated on a better understanding of the poverty-growth-inequality relationship, particularly in SSA.

Growth has traditionally been considered the main engine for poverty reduction. However, attention to the importance of income distribution in poverty reduction seems to be growing. ${ }^{1}$ Using evidence for single countries, both Datt and Ravallion (1992) and Kakwani (1993) decompose poverty changes into effects attributable to: (1) income growth and (2) changes in income distribution. Based on cross-country African data, Ali and Thorbecke (2000) find that poverty responds more to income distribution than to growth. More recent studies have focused on the role of initial inequality in the impact of growth on poverty. For example, Ravallion (1997) and Easterly (2000) estimate the income-growth elasticity of poverty as a decreasing function of inequality. 2 Similarly, using the rather limited sample of 32 paired rural and urban sectors for 16 SSA countries employed in Ali and Thorbecke (2000), Fosu (2008) arrives at a similar conclusion about the inequality impact on the income elasticity of poverty. Adams (2004) also finds that a sub-sample of countries with a higher level of inequality exhibits a smaller growth elasticity of poverty. On the assumption of a lognormal distribution of income, Bourguignon (2003) and Epaulard (2003) estimate equations that assume that the income-growth elasticity, for instance, depends on the ratio of the poverty line to mean income as well as on initial inequality. Based on similar specifications as in Bourguignon (2003), Kalwij and Verschoor (2007) reach similar conclusions as in Bourguignon (2003) and Epaulard (2003), and emphasize regional diversity in poverty responsiveness to growth and inequality.

Complementing the above studies, the current paper provides a focus on SSA, 3 where poverty reduction is likely to constitute a particularly important challenge as compared

1 For elaboration on the growing importance of income distribution, see for instance, Bruno et al. (1998), Chen and Ravallion (1997), and World Bank (2006b).

2 To simplify the exposition, we shall ignore the negative sign and use 'income-growth elasticity of poverty' to signify its magnitude.

3 Except for Ali and Thorbecke (2000) and Fosu (2008), none of the above studies focus on SSA. However, the specification used in the former study implicitly assumes that the elasticity of poverty with respect to income is independent of the level of inequality. Furthermore, while it estimates the 
to other regions of the world. The study examines the extent to which inequality influences the impact of growth on changes in poverty for SSA relative to other regions, exploring the issue of whether SSA fits the global pattern. With historical data showing both low growth rates and high levels of inequality in the African region, shedding light on this hypothesis should usefully inform policy.

The current paper deviates from especially the most recent comprehensive study on the subject (Kalwij and Verschoor 2007) in several respects. First, it extends the analysis to other measures beyond the headcount ratio used in that study, namely, the depth and severity of poverty measures. As is well understood in the literature, these two additional measures convey more in-depth information about the state of poverty not reflected by the headcount ratio alone. Second, the present paper focuses on SSA, rather than the implicit interest in particularly Eastern Europe and Central Asia as exhibited by the above study. Indeed, such an interest led the authors to employ the US\$2-per-day measure of poverty rather than the US\$1 standard. 4 Compared to other regions, however, SSA seems to have performed worse over time on the US\$1 daily standard (see Table 1). For instance, using South Asia (SAS) as the comparator, the US\$2 measure shows only a marginal change in the ratio of SSA to SAS between 1981 and 2004. In contrast, the US $\$ 1$ standard reveals a substantial deterioration in the relative SSA/SAS poverty rate picture, with this SSA/SAS ratio rising by nearly 50 percentage points between 1981 and 2004 when the US\$1 measure is employed. This compares with a rise of only 10 percentage points, over the same period, on the basis of the US\$2 standard. Thus, if the poverty-reduction challenge for African countries is to be met head on, the US\$1 measure, an indicator of extreme poverty, appears to warrant special consideration, as is done in the present study.

Table 1

Historical poverty record (headcount ratio in \%): SSA versus South Asia (SAS)

\begin{tabular}{ccccc}
\hline \multicolumn{5}{c}{ A. US\$1 Standard } \\
\hline SSA & 1981 & 1987 & 1993 & 2004 \\
SAS & 42.3 & 47.2 & 45.5 & 41.1 \\
SSA/SAS & 49.6 & 45.1 & 36.9 & 30.8 \\
& 85.3 & 104.7 & 123.3 & 133.4 \\
& & & \\
SSA & 1981 & B. US\$2 Standard & & 2004 \\
SAS & 74.5 & 1987 & 1993 & 72.0 \\
SSA/SAS & 88.5 & 77.4 & 76.1 & 77.1 \\
\hline
\end{tabular}

Source: World Bank (2007).

interactive inequality-income effect using the rather limited SSA sample of Ali and Thorbecke, the latter study employs the headcount ratio only, is based on level data, and provides no comparative evidence.

4 The use of the US\$1 standard would have resulted in zero values for a large number of countries in the Eastern Europe and Central Asia region, thus excluding them from the study. 
The paper first presents, in Section 2, a theoretical framework where various hypotheses regarding the impacts of growth and inequality are presented. Several specifications are estimated in Section 3 for the headcount, gap and squared gap measures of poverty, using 1977-2004 unbalanced panel data for SSA relative to the rest of the developing world. The implied elasticities are then computed and discussed, focussing on the role of inequality in the impact of income growth on changes in poverty. Of particular concern here is not only the responsiveness of poverty to income growth for SSA as a region relative to the rest of the developing world, but also the variation in this responsiveness among African countries. For purposes of poverty reduction, such an approach is important for efficient country-specific policymaking in SSA. Section 4 concludes the paper.

\section{The model}

To derive the estimating equations, 5 we follow the literature and define an individual as 'poor' when his/her income falls short of 'basic needs' in a given locality. 6 Furthermore, the lower its value, the more likely that income will be below basic needs, so that the level of poverty should decrease with income. Hence, assuming a Cobb-Douglas relationship, ${ }^{7}$ we may specify the poverty function as:

$$
P=P(Y)=A Y^{a}
$$

where $P$ is the level of poverty and $Y$ is income; $A$ reflects initial poverty independently of income and is expected to be positive, while $a$ is the income-elasticity of poverty and its sign should be negative. A linearized differenced version of Equation (1) is of the form:

$$
p=a_{1}+a_{2} y
$$

where $p$ and $y$ are the respective growth rates of poverty and income; $a_{2}$ is the elasticity of poverty changes with respect to income growth and $a_{1}$ the growth of poverty at a constant level of income.

Suppose, however, that the socio-political environment, such as the nature of income distribution, influences both $a_{1}$ and $a_{2}$. For example, a country with a more equally distributed income should exhibit a higher rate at which income growth is transformed

5 Although the current derivation is similar to that in Fosu (2008), that study derived and estimated the poverty function in (logarithmic) levels rather in growth rates as is done here.

6 For proponents of the basic-needs approach see, for example, Hicks and Streeten (1979) and Adelman (1975); however, Goldstein (1985) and Ram (1985) suggest a 'trickle-down' approach to growth. Poverty will be measured by the Foster-Greer-Thorbecke (FGT) poverty measures: the headcount ratio $\mathrm{P}_{0}$ as the relative frequency below the poverty line; the poverty gap $\mathrm{P}_{1}$ reflecting how far incomes are below the line; and the squared gap $\mathrm{P}_{2}$ as a measure of the severity of poverty (see Foster, Greer and Thorbecke 1984).

7 The assumption may be justified by the special properties of the Cobb-Douglas function (CDF) that increasing income would reduce poverty at a decreasing rate, since the farther incomes are below the poverty line the greater the effort required to raise such incomes above the poverty line. Of course, many other functions would satisfy this condition as well; however, the CDF is adopted here to simplify the analytical exposition, while the FGT poverty measures will be used in the empirical analysis. 
to poverty reduction, ceteris paribus. Similarly, acceleration in inequality is likely to raise the rate at which poverty is increasing. The growth in poverty will, furthermore, be faster as initial income is higher, for a larger portion of the non-poverty implied by the higher income would be transformed into poverty by the acceleration in inequality. Hence $a_{1}$ and $a_{2}$ may be expressed parametrically in linear form as:8

$$
\begin{aligned}
& a_{1}=a_{11}+a_{12} g+a_{13} Y^{I} \\
& a_{2}=a_{21}+a_{22} G^{I}
\end{aligned}
$$

where $Y^{I}$ and $G^{I}$ are initial levels of income and inequality (Gini), respectively; $a_{11}, a_{12}$ and $a_{13}$ are the parametric coefficients independent of income growth; and $a_{21}$ and $a_{22}$ are the coefficients associated with the income-growth impact. Incorporating Equations (3) and (4) into Equation (2) yields:

$$
p=c_{1}+c_{2} y+c_{3} g+c_{4} y G^{I}+c_{5} g Y^{I}
$$

where $c_{1}=a_{11}$ is the intercept, $c_{2}=a_{21}$ is the (independent) impact of $y$ on $p$ (when $g=G^{I}=0$ ), $c_{3}=a_{12}$ is the (independent) impact of $g$ (when $y=Y^{I}=0$ ), $c_{4}=a_{22}$ is the effect of $y$ interactively with $G^{I}$, and $c_{5}=a_{13}$ is the effect of $g$ interactively with $Y^{I}$.

The coefficients in Equation (5) are interpreted next. The sign of $c_{2}$, which is the independent impact of $y$ (with $G^{I}=0$ ), is anticipated to be negative, for an increase in income growth should reduce the growth of poverty. The sign of $c_{3}$ is expected to be positive, since accelerating inequality would exacerbate poverty increases. As $c_{4}$ represents the effect of initial inequality on the impact of $y$, its sign is anticipated to be positive, for a higher level of inequality would lower the poverty-reducing effect of growth. The sign of $c_{5}$ is also expected to be positive, so that, as argued above, at a higher initial income acceleration in inequality would map a larger portion of the income distribution into poverty increases.

According to Equation (2), a rise in income growth should reduce poverty proportionately. This case is akin to the Dollar and Kraay (2002) proposition that all income groups would benefit proportionately from growth increases, thus suggesting no special role for income distribution in the poverty-growth relationship. In contrast, Equation (5) implies not only that rising inequality has implications for poverty, but also that the effect of growth on poverty changes would depend on the level of inequality. Equation (5) is similar to the empirical specifications of Ravallion (1997) and Easterly (2000), both of whom postulated that inequality would lessen the impact of growth on poverty reduction. However, the present equation further incorporates the growth of inequality, both as a separate independent variable and interactively with initial income.

Equation (5) is the main model of interest; however, other specifications are additionally estimated. One of these is the constrained version of Equation (5), where the interactive effects associated with growth and poverty changes are both assumed to be zero. This constrained model is presented as:

8 For an exposition of a variant of the present framework involving the production function, see for example Fosu (2001). 


$$
p=c_{1}+c_{2} y+c_{3} g
$$

Another alternate model is based on the assumption that the income distribution is lognormal, as estimated by Bourguignon (2003), Epaulard (2003), and Kalwij and Verschoor (2007), for instance. That model is of the form: 9

$$
p=d_{1}+d_{2} y+d_{3} g+d_{4} y(Z / Y)+d_{5} y G^{I}
$$

where $Z / Y$ is the ratio of the poverty line $Z$ to income $Y$; the remaining variables are as defined above; and $d_{j}(\mathrm{j}=1,2, \ldots, 5)$ are the respective coefficients to be estimated. As in Equation (5), $d_{2}$ and $d_{3}$ are expected to be negative and positive, respectively. However, Equation (6) postulates that the income-growth elasticity of poverty depends not only on the initial level of inequality, but also on the mean income relative to the poverty line. It is anticipated that $d_{4}$ will be positive, consistent with the hypothesis, based on the lognormal income distribution, that a larger income would have associated with it a higher (absolute value of) income-growth elasticity. As in Equation (5), $d_{5}$ is expected to be positive as well.

\section{Data, estimation, and results}

\subsection{The data}

The data used in the present analysis are derived from a World Bank global sample, which provides 353 usable unbalanced panel observations over 1977-2004, of which 51 are from SSA and 302 from non-SSA countries. 10 There are 24 SSA and 61 non-SSA countries in the sample, though country representation differs substantially, depending on the availability of survey data. For example, China and India have the greatest representation, with 28 and 23 observations, respectively, while the country with the largest representation in the SSA sample, Cote d'Ivoire, has only six observations. To provide comparability across countries, the same poverty line, US\$32.74 per month (translating roughly to the international standard of US\$1 per day in real 1993 PPPadjusted dollars), is applied to all countries and over time. Measures of the headcount ratio, p0, poverty gap, p1, and poverty gap squared, p2, are analysed using the above equations.

The Appendix table presents the summary statistics for SSA and non-SSA samples in both levels and growth rates. It shows the mean poverty rate (headcount ratio) for SSA to be nearly four times that of non-SSA. Similarly, p1 and p2 are more than five and six

9 This model is specified by Bourguignon (2003) as the 'improved standard model 1', which concentrates on the income-growth elasticity of poverty. Similarly, Epaulard (2003) uses a similar specification and finds, based on the US\$2 per day poverty standard for a global sample involving 99 economic episodes from Chen and Ravallion (1997: 20), that 'the higher the inequality, the lower the absolute value of the elasticity; the higher the mean income, the higher the absolute value of the elasticity'. Bourguignon (2003) additionally estimates an extended version of this equation: $\mathrm{p}=\mathrm{d}_{1}+$ $\mathrm{d}_{2} y+\mathrm{d}_{3} g+\mathrm{d}_{4} y(Z / Y)+\mathrm{d}_{5} y G^{I}+\mathrm{d}_{6} g(Z / Y)+\mathrm{d}_{7} g G^{I}$, the same version also estimated by Kalwij and Verschoor (2007). However, we opt for Equation (6) in order to concentrate on the income-growth elasticity, as the last two terms in this equation are on the inequality elasticity. As will be further argued later, the extended model yields some counter-intuitive empirical results.

10 The data source is: http://iresearch.worldbank.org/PovcalNet/jsp/index.jsp 
times, respectively, larger for SSA, whose mean income is estimated at less than one half of that for non-SSA. Meanwhile, the level of inequality, measured by the Gini ratio, is only slightly larger for SSA. The growth rates presented in the table are not directly comparable across countries or samples, though, as they are calculated for different time intervals depending on the availability of survey data. The main rationale for reporting them here is to make available all the relevant statistics on which the main results of the present paper are based.

\subsection{Estimation and results}

Both the fully specified and constrained ( $\mathrm{c} 4=\mathrm{c} 5=0$ ) versions of Equation (5), as well as Equation (6), are estimated using random-effects (RE) and country-fixed effects (FE), with p0, p1, and p2 as measures of p.11 Based on the Hausman-specification test statistics (reported in Table 2), the RE estimates are judged to be statistically superior to the FE and are thus reported in Table 2: as specifications (5'), (5) and (6) in Tables 2A, $2 \mathrm{~B}$ and $2 \mathrm{C}$, respectively. 12 For each model, we provide two sets of coefficients, along with their respective $t$ ratios in parentheses. The first set corresponds to non-SSA, and the second (righthand side and bolded) to the difference in coefficients, that is, SSA less non-SSA.13 This difference-in-coefficients estimation and reporting procedure should help delineate the extent to which SSA is different from the global average. For example, if a given non-SSA coefficient is positive (negative), while the bolded coefficient is negative (positive), then the SSA effect is less than the 'global' effect by the amount of the bolded value, suggesting a lesser responsiveness of the SSA poverty rate to the respective variable.

We discuss, first, the results from specification (5') where income growth, $y$, and changes in inequality (Gini), $g$, enter independently into the poverty equation (see Table 2A). As expected, these coefficients are statistically negative and positive, respectively, in all equations, implying that a rise in income growth would reduce the rate of poverty increases, while acceleration in inequality would exacerbate poverty growth. In addition, we note that the bolded coefficients have the opposite signs as the main coefficients, and are furthermore statistically significant, suggesting that the respective degrees of poverty responsiveness for SSA are lower than for the remaining regions. That is, compared to the rest of the developing world, SSA poverty rates would exhibit low responsiveness to growth acceleration or to deceleration in inequality. This finding appears to hold for all the three poverty measures.

11 The RE model is estimated using the Generalized Least Squares (GLS). Note that the results reported by Bourguignon (2003) and Epaulard (2003), for instance, are based on Ordinary Least Squares (OLS).

12 We fail to reject the null hypothesis that the more efficient RE estimates are also consistent, rendering the RE results statistically preferable. However, the FE estimates, which are very similar to those of the $\mathrm{RE}$, are shown in the online appendix table 1 in order to lend further credibility to the empirical results reported in the paper.

13 That is, for each coefficient, the SSA coefficient is the non-SSA coefficient plus the bolded coefficient. 
Table 2

Inequality, growth, and poverty: SSA versus non-SSA

Regression results (random effects); dependent variables $=p j(j=0,1$, and 2 )

Table 2A, specification (5')

\begin{tabular}{|c|c|c|c|c|c|c|}
\hline \multicolumn{3}{|c|}{ p0 } & \multicolumn{2}{|l|}{$\mathrm{p} 1$} & \multicolumn{2}{|l|}{$\mathrm{p} 2$} \\
\hline \multirow[t]{2}{*}{$y$} & $-2.870^{a}$ & $1.750^{\mathrm{a}}$ & $-3.116^{a}$ & $1.152^{\mathrm{a}}$ & $-3.246^{a}$ & $1.168^{b}$ \\
\hline & $(-17.67)$ & $(5.26)$ & $(-10.26)$ & $(4.21)$ & $(-8.34)$ & (2.52) \\
\hline \multirow[t]{2}{*}{$g$} & $5.116^{a}$ & $-3.981^{\mathrm{a}}$ & $5.878^{\mathrm{a}}$ & $-3.758^{a}$ & $5.968^{\mathrm{a}}$ & $-3.085^{a}$ \\
\hline & (15.43) & $(-7.04)$ & (8.18) & $(-5.02)$ & (6.53) & $(-3.21)$ \\
\hline$y G^{\prime}$ & -- & -- & -- & -- & -- & -- \\
\hline$g Y^{\prime}$ & -- & -- & -- & -- & -- & -- \\
\hline$y(Z / Y)$ & -- & -- & -- & -- & -- & -- \\
\hline \multirow[t]{2}{*}{ Intercept } & $-0.049^{c}$ & 0.046 & -0.069 & 0.075 & -0.086 & 0.102 \\
\hline & $(-1.66)$ & $(0.61)$ & $(-1.60)$ & (1.08) & $(-1.40)$ & (1.05) \\
\hline Adj. $R^{2}$ & 0.55 & & 0.48 & & 0.33 & \\
\hline SEE & 0.49 & & 0.66 & & 0.94 & \\
\hline \multirow[t]{2}{*}{$\mathrm{H}$} & 1.41 & & 0.81 & & 3.60 & \\
\hline & [0.84] & & [0.94] & & {$[0.46]$} & \\
\hline
\end{tabular}

Table 2B, specification (5)

\begin{tabular}{|c|c|c|c|c|c|c|}
\hline \multicolumn{3}{|c|}{$\mathrm{p} 0$} & \multirow{2}{*}{$\frac{\mathrm{p} 1}{-6.217^{\mathrm{a}}}$} & \multicolumn{3}{|c|}{$\mathrm{p} 2$} \\
\hline \multirow[t]{2}{*}{$y$} & $-5.976^{a}$ & $4.034^{a}$ & & $3.120^{c}$ & $-5.906^{a}$ & 1.815 \\
\hline & $(-5.23)$ & $(2.94)$ & $(-5.12)$ & $(1.70)$ & $(-4.19)$ & $(0.75)$ \\
\hline \multirow[t]{2}{*}{$g$} & $2.974^{\mathrm{a}}$ & $-3.066^{a}$ & $3.501^{\mathrm{a}}$ & $-3.054^{c}$ & $3.640^{\mathrm{b}}$ & -2.606 \\
\hline & (3.81) & $(-2.78)$ & (3.05) & $(-1.66)$ & (2.09) & $(-0.97)$ \\
\hline \multirow[t]{2}{*}{$y G^{\prime}$} & $7.288^{\mathrm{a}}$ & $5.469^{b}$ & $7.092^{\mathrm{a}}$ & -3.966 & $6.176^{\mathrm{b}}$ & -1.810 \\
\hline & (3.10) & $(-1.97)$ & $(2.77)$ & $(-1.05)$ & (2.01) & $(-0.36)$ \\
\hline \multirow[t]{2}{*}{$g Y^{\prime}$} & $0.016^{\mathrm{a}}$ & 0.006 & $0.017^{b}$ & 0.012 & 0.017 & 0.015 \\
\hline & $(2.78)$ & $(0.34)$ & $(2.06)$ & $(0.38)$ & (1.37) & $(0.34)$ \\
\hline$y(Z / Y)$ & -- & -- & -- & -- & -- & -- \\
\hline \multirow[t]{2}{*}{ Intercept } & -0.020 & 0.020 & -0.020 & 0.046 & -0.059 & 0.073 \\
\hline & $(-0.64)$ & $(0.49)$ & $(-0.64)$ & $(0.72)$ & $(-0.96)$ & $(0.80)$ \\
\hline Adj. $R^{2}$ & 0.61 & & 0.52 & & 0.35 & \\
\hline SEE & 0.46 & & 0.63 & & 0.92 & \\
\hline \multirow{2}{*}{$\mathrm{H}$} & 1.25 & & 3.16 & & 6.0 & \\
\hline & [0.99] & & [0.92] & & [0.65] & \\
\hline
\end{tabular}


Table 2C, specification (5)

\begin{tabular}{|c|c|c|c|c|c|c|}
\hline \multicolumn{3}{|c|}{$\mathrm{p} 0$} & \multirow{2}{*}{$\frac{p 1}{-8.233^{a}}$} & \multicolumn{3}{|c|}{$\mathrm{p} 2$} \\
\hline \multirow[t]{2}{*}{$y$} & $-8.802^{a}$ & $5.471^{\mathrm{a}}$ & & 2.887 & $-7.004^{a}$ & -0.388 \\
\hline & $(-4.68)$ & (2.59) & $(-4.23)$ & (1.13) & $(-3.22)$ & $(-0.12)$ \\
\hline \multirow[t]{2}{*}{$g$} & $5.428^{a}$ & $-4.323^{a}$ & $6.158^{a}$ & $-4.080^{a}$ & $6.190^{a}$ & $-3.339^{a}$ \\
\hline & (9.58) & $(-7.37)$ & $(9.16)$ & $(-5.82)$ & $(6.93)$ & $(-3.58)$ \\
\hline \multirow[t]{2}{*}{$y G^{\prime}$} & $11.414^{\mathrm{a}}$ & $-7.406^{b}$ & $10.316^{a}$ & -3.705 & $8.219^{b}$ & 0.969 \\
\hline & $(3.45)$ & $(-2.06)$ & $(2.88)$ & $(-0.86)$ & $(2.03)$ & (0.18) \\
\hline$g Y^{\prime}$ & -- & -- & -- & -- & -- & -- \\
\hline \multirow[t]{2}{*}{$y(Z / Y)$} & $4.083^{a}$ & $-3.504^{b}$ & $2.578^{c}$ & -1.541 & 0.992 & 0.714 \\
\hline & $(2.84)$ & $(-2.32)$ & $(1.81)$ & $(-0.94)$ & $(0.57)$ & $(0.34)$ \\
\hline \multirow[t]{2}{*}{ Intercept } & -0.025 & 0.024 & -0.049 & 0.057 & -0.07 & 0.095 \\
\hline & $(-1.85)$ & $(0.52)$ & $(-1.14)$ & $(0.79)$ & $(-1.15)$ & $(0.94)$ \\
\hline Adj. $\mathrm{R}^{2}$ & 0.61 & & 0.51 & & 0.34 & \\
\hline SEE & 0.46 & & 0.64 & & 0.94 & \\
\hline \multirow[t]{2}{*}{$\mathrm{H}$} & 3.91 & & 1.89 & & 4.20 & \\
\hline & [0.79] & & [0.97] & & {$[0.76]$} & \\
\hline
\end{tabular}

Notes: ${ }^{a} 0.01$ significance (2-tailed); ${ }^{b} 0.05$ significance; ${ }^{c} 0.10$ significance.

Estimation was conducted on the whole panel sample (size of 353) using 'differencesin-coefficients'. For each set of results, the first column represents non-SSA estimates while the next righthand set (bolded) is the set of estimates for the SSA differential (that is, SSA less non-SSA), so that the sum of the two estimates for each row represents the SSA coefficient estimate for the respective explanatory variable. Under the null hypothesis that the coefficient parameter is the same for SSA and non-SSA, the right-hand estimates would not be significantly different from zero. $\mathrm{H}$ is the Hausman test statistic for choice between the Random Effects (RE) and Fixed Effects (FE) models, with the respective $p$-values in square brackets. The figures in parentheses are t-ratios based on robust standard errors; Adj. $\mathrm{R}^{2}$ and SEE are, respectively, the coefficient of determination and standard error of estimate. All other variables are as defined in the Appendix table. Specifications (5'), (5) and (6) are the estimated Equations (5'), (5) and (6) in the text, respectively.

We now turn to the results, also shown in Table 2 (see Table 2B), from estimating the fully specified version of Equation (5), that is, specification (5). It is noteworthy that the model provides a better fit generally than specification (5'), on the basis of the SEE and adjusted $\mathrm{R}^{2}$, implying that initial income and inequality do indeed matter. Moreover, as expected, the results imply that higher levels of inequality would reduce the incomegrowth elasticity of poverty, and that a larger initial income level would exacerbate the pernicious effect on poverty associated with inequality increases. With respect to the relative impact on SSA, the results further suggest that the magnitudes of the coefficients are generally smaller for SSA. Focussing on the income-growth impact, we obtain for the p0 measure an estimate of $-6.0+7.2 G^{I}$ for non-SSA, compared with $-1.9+1.8 G^{I}$ for SSA. The implied elasticity (absolute-valued) estimates that the means are 1.1 and 3.0 for SSA and non-SSA, respectively. This differential estimate is similar to that obtained under the constrained model, specification $\left(5^{\prime}\right)$ (see Table 2A versus Table 2B).

We consider next in Table 2C the results for Equation (6), which is based on the lognormal income distribution; these results are presented as specification (6). The 
outcome is as anticipated, with higher increases in income and in inequality leading to reductions and rises in the rates of poverty changes, respectively. Furthermore, the income-growth elasticity decreases with inequality but increases with mean income. On the basis of the SEE and adjusted $\mathrm{R}^{2}$, this model performs better than the 'naïve' specification (5'), consistent with the finding by Bourguignon (2003), for instance. However, it does not outperform specification (5), where the income-growth elasticity depends on initial inequality but not necessarily on income. Actually, in cases involving p1 and p2, specification (5) appears to perform slightly better than specification (6), in terms of goodness of fit, a result that seems consistent with Bourguignon's finding that the lognormal approximation does not fare as well for the higher-order measures of poverty.

Nonetheless, the results for specification (6) are as expected. For example, as in specification (5), for p0 the coefficients of $y$ and $g$ are statistically negative and positive, respectively, indicating the poverty-reducing effect of income growth and the povertyexacerbating impact of increasing inequality. Furthermore, the statistically positive coefficient of $y G^{I}$ implies that a higher initial inequality would reduce the rate at which income growth lowers the rate of poverty increases. Finally, the coefficient of $y(Z / Y)$ is statistically positive, implying that the poverty-reducing effect of income growth is greater as the mean income (relative to the poverty line) is higher. The results for $\mathrm{p} 1$ and p2 are similar to those of p0; however, the significance of the coefficient of $y(Z / Y)$ seems to wane with these higher-order poverty measures. Apparently, the level of income is less important for influencing the poverty-reducing effect of income growth for poverty depth and severity, rather than for the headcount. This finding contrasts with that for inequality, whose interactive effect is significant across all the three poverty measures.

Comparing our results of specification (6) with those of Bourguignon, we observe that ours for p0 are strikingly similar to his. 14 In contrast, however, the current p1 results, which are similar to those of $\mathrm{p} 0$, differ considerably from the $\mathrm{p} 1$ results reported by Bourguignon.15 In particular, Bourguignon's p1 results show the coefficient of the interactive variable ( $y$ with the initial Gini) as negative, which suggests rather counterintuitively that a higher level of inequality would increase the income-growth elasticity of poverty. 16 In any case, for the purpose of the present study, and consistent with the

14 Based also on the US\$1-per-day standard, Bourguignon (2003, table 1.1, column 3) reports the following results based on a sample of 114 growth spells in the 1980s and 1990s as (using the present symbols):

$\mathrm{p} 0=0.0837-6.3518 y+5.2863 g+3.9678 y(Z / Y)+7.0039 y G^{I} \quad \mathrm{R}^{2}=0.555$

(0.0349) (1.2451) (0.6529) (1.1662) (2.4586)

where the figures in parentheses are the respective standard errors. These compare well with our p0 results reported in Table 2 as (with standard errors in parentheses as well for ease of comparison):

$\mathrm{p} 0=-0.059-8.802 y+5.428 g+4.083 y(Z / Y)+11.414 G^{I} \quad$ Adj. $\mathrm{R}^{2}=0.61$

$\begin{array}{llll}(0.032) \quad(2.101) & (0.567) \quad(1.438) \quad \text { (3.308) }\end{array}$

15 Bourguignon (2003, table 1.2, column 3) reports the following results for p1 (using the present symbols; standard errors in parentheses):

$\mathrm{p} 1=0.1683-0.4101 y+7.1231 g-0.9647 y(Z / Y)-2.4774 G^{I} \quad \mathrm{R}^{2}=0.2308$

$\begin{array}{llll}(0.0796) & (2.8388) & (1.4885) \quad(2.6588) \quad(5.6055)\end{array}$

16 Indeed, it is likely that these results for p1 in Bourguignon's table 1.2 are incorrectly reported, since they seem to substantially counter his results for $\mathrm{p} 0$. As a further indication of possible misreporting, it is stated in his table 1.2 that 'all coefficients are significantly different from zero at the 1 per cent probability level except the intercept'; yet as the results duplicated for p1 above show, only the g 
results of specifications (5') and (5) discussed above, our estimates from specification (6) also suggest lower responsiveness in SSA of poverty to income growth.

To further elucidate the results, we compute the respective income-growth elasticities based on specifications (5'), (5) and (6) as:17

$$
\begin{aligned}
& \varepsilon_{y}=c_{2} ; \varepsilon_{g}=c_{3}\left(\text { with } c_{4}=c_{5}=0\right) \\
& \varepsilon_{y}=c_{2}+c_{4} G^{I} ; \varepsilon_{g}=c_{3}+c_{5} Y^{I} \\
& \varepsilon_{y}=d_{2}+d_{4}(Z / Y)+d_{5} G^{I} ; \varepsilon_{g}=d_{3}
\end{aligned}
$$

where all variables and coefficients are as defined in Equations (5) and (6). The results are presented in Table 3, which reports the point estimates at the respective means as well as the interval (range) estimates for the income-growth elasticity, based on the maximum and minimum values of $G^{I}$, where applicable. The estimates are presented separately for SSA and non-SSA.18

Table 3

Partial elasticities of changes in poverty with respect to growths in income and inequality, SSA versus non-SSA

\begin{tabular}{llll}
\hline Specification (5') & & Specification (5) & Specification (6) \\
\hline SSA countries & & & \\
p0 & & & \\
$y$ & -1.123 & $-1.154(-1.434,-0.874)$ & $-1.143(-1.781,-0.506)$ \\
$g$ & 1.136 & 1.287 & 1.105 \\
& & & \\
p1 & & & $-1.682(-2.733,-0.631)$ \\
$y$ & -1.650 & $-1.697(-2.194,-1.200)$ & 2.078 \\
$g$ & 2.121 & 2.264 & \\
p2 & & & \\
\hline
\end{tabular}

coefficient is significantly different from zero. Bourguignon, however, does not report any results for p2, so that there is no basis for comparison between his and our estimates.

17 Note that Bourguignon does not actually present the elasticities derivable from his estimated equations.

18 Also computed were the elasticities based on the extended version of Equation (6): $\mathrm{p}=\mathrm{d}_{1}+\mathrm{d}_{2} y+\mathrm{d}_{3} g$ $+\mathrm{d}_{4} y(Z / Y)+\mathrm{d}_{5} y G^{I}+\mathrm{d}_{6} g(Z / Y)+\mathrm{d}_{7} g G^{I}$. The estimates of the income-growth elasticities were found to be similar to those reported here in Table 3 , and are available upon request. However, we prefer to report the present estimates mainly because the remaining two terms refer to the effect of changes in inequality rather than income growth, and secondarily because we found rather counter-intuitive the estimates for the last two terms of the above extended equation. In particular, the negative sign of $\mathrm{d}_{6}$ suggests that a high level of initial inequality would decrease the rate at which further increases in inequality would raise poverty. For the headcount poverty rate, for instance, we estimated for nonSSA (not presented in Table 2):

$$
\mathrm{p}_{0}=-0.053-10.503 y+15.345 g+14.100 y G^{I}+6.326 y(Z / Y)-17.200 g G^{I}-12.592 g(Z / Y)
$$

which is comparable to the estimated 'Standard Model 2' by Bouguignon (2003, table 1.1, column 5) of:

$$
\begin{aligned}
\mathrm{p}_{0}= & 0.098-7.871 y+21.561 g+9.687 y G^{I}+3.948 y(Z / Y)-20.360 g G^{I}-16.390 g(Z / Y) \\
& (0.032)(1.131) \quad(4.121) \quad(2.210)
\end{aligned}
$$

where figures in parentheses in both equations are standard errors. 


\begin{tabular}{llll}
\hline$y$ & -2.078 & $-2.135(-2.829,-1.441)$ & $-2.120(-3.581,-0.659)$ \\
$g$ & 2.883 & 3.039 & 2.851 \\
\multicolumn{2}{l}{$\begin{array}{l}\text { Non-SSA countries } \\
\text { p0 }\end{array}$} & & \\
$y$ & & & \\
$g$ & -2.870 & $-2.962(-4.740,-1.393)$ & $-2.868(-5.675,-0.391)$ \\
& 5.116 & 5.557 & 5.428 \\
p1 & & \\
$y$ & & & \\
$g$ & -3.166 & $-3.260(-5.004,-1.721)$ & $-3.190(-5.727,-0.951)$ \\
& 5.878 & 6.254 & 6.158 \\
p2 & & & \\
$y$ & & & $-3.291(-5.313,-1.508)$ \\
$g$ & -3.246 & $-3.331(-4.850,-1.990)$ & 6.190 \\
\hline
\end{tabular}

Notes: Partial elasticities are computed based on Equations (7)-(9) of the text, using the respective estimates from Table 2, that is specifications (5), (5') and (6). The point estimates are at the means of the relevant variables, and the interval estimates are ranges based on the sample minimum and maximum values of $G^{\prime}$, respectively. All variables are as defined in the Appendix table.

As the results in Table 3 indicate, the elasticity estimates at the means are similar across specifications (for both SSA and non-SSA), suggesting that if one is interested in the average values only, the simplest specification (5') will do just as well. Irrespective of the specification, however, the results between SSA and non-SSA appear to differ considerably, with the SSA elasticities substantially less than those of non-SSA. For example, the income-growth elasticity for non-SSA is nearly three times that of SSA, so that accelerating growth in SSA would bring forth a much smaller reduction in poverty than would be the case in non-SSA. This result is similar to those reported by others; for example, Kalwij and Verschoor (2007: 818, table 4) present for the mid1990s estimates, based on the US $\$ 2$ poverty standard, of -0.71 and -1.31 for SSA and all regions, respectively. If anything, the present result on the basis of the US\$1 measure shows an even larger SSA/non-SSA differential.

Furthermore, the degree of the SSA/non-SSA differences in the income-growth elasticities appears to depend on the poverty measure, with the differential for $\mathrm{p} 0$ the largest (2.6 times), followed by that for $\mathrm{p} 1$ (2.0 times), and with the differential for $\mathrm{p} 2$ as the least (1.6 times). Thus, the overestimation of the growth impact that may result from using the global estimate for SSA would appear to be most consequential for p0, which is arguably the most popular policy target variable among the various poverty measures. Moreover, we observe that the non-SSA/SSA ratios of elasticities are 3.0 and 5.0, respectively, for income-growth and changes in inequality (Table 3). This result provides support for the notion that in a relative sense growth acceleration, compared with reductions in inequality, would be more effective in SSA than in non-SSA, notwithstanding the finding that the poverty-reduction efficacy of either inequality or income growth would be higher for non-SSA.

The estimated ranges, also shown in Table 3, indicate that there is a wide disparity in income-growth elasticities across countries, thanks to inequality differences, within both SSA and elsewhere in the developing world. For example, for non-SSA, Brazil's 
income-growth elasticity is estimated at -1.6, compared with China's of roughly -3.4.19 The cross-country differences seem less dramatic within SSA, though, where a smaller range is estimated (Table 3), due to the lower income-growth elasticities and the smaller sample that may have missed extreme values. 20 The results suggest that even if the estimates are restricted to the current SSA sample, there are large cross-country disparities in the income-growth elasticities, with the maximum elasticity being at least roughly twice the minimum. 21

Table 4 reports predicted values of the income-growth elasticity for all the 30 SSA countries available in the World Bank database based on the most recent data. Note that this sample includes as well six additional countries that were excluded from the above empirical analysis due to the lack of more than one-period observations required to generate growth rates. As the table shows, there is substantial variation in the estimates, ranging from 0.63 in Namibia to 1.41 in Ethiopia for p0 under specification (5) where initial inequality alone drives the results. A like observation is made under specification (6), which takes into account as well the income level relative to the poverty line: from 0.26 in Namibia to 1.80 in Ethiopia. The results for the other higher-order poverty measures are similar to those of p0, though the ranges appear to increase with the order, that is, there is a larger range for $\mathrm{p} 1$ than for $\mathrm{p} 0$, and for $\mathrm{p} 2$ than for $\mathrm{p} 1$.

Table 4

Predicted income-growth elasticity of poverty (in absolute values), SSA countries

\begin{tabular}{llcccccr}
\hline & & \multicolumn{3}{c}{ Specification $(5)$} & \multicolumn{3}{c}{ Specification (6) } \\
\hline Country & & p0 & p1 & p2 & p0 & p1 & p2 \\
Benin* & BEN & 1.263 & 1.890 & 2.405 & 1.465 & 2.223 & 2.906 \\
Botswana & BWA & 0.870 & 1.191 & 1.429 & 0.725 & 1.025 & 1.313 \\
Burkina Faso & BFA & 1.245 & 1.859 & 2.362 & 1.422 & 2.152 & 2.806 \\
Burundi & BDI & 1.196 & 1.772 & 2.240 & 1.161 & 1.700 & 2.109 \\
Cameroon & CMR & 1.158 & 1.704 & 2.146 & 1.329 & 2.014 & 2.662 \\
Cape Verde* & CPV & 1.053 & 1.518 & 1.885 & 1.221 & 1.853 & 2.498 \\
Central African Republic* & CAF & 0.863 & 1.180 & 1.413 & 0.410 & 0.463 & 0.394 \\
Côte d'Ivoire & CIV & 1.091 & 1.584 & 1.978 & 1.202 & 1.807 & 2.387 \\
Ethiopia & ETH & 1.414 & 2.159 & 2.781 & 1.798 & 2.770 & 3.661 \\
Gambia & GMB & 1.058 & 1.527 & 1.898 & 1.113 & 1.658 & 2.172 \\
Ghana & GHA & 1.225 & 1.823 & 2.312 & 1.303 & 1.944 & 2.484 \\
Kenya & KEN & 1.194 & 1.768 & 2.235 & 1.404 & 2.137 & 2.830 \\
Lesotho & LSO & 0.832 & 1.124 & 1.335 & 0.604 & 0.820 & 1.011 \\
Madagascar & MDG & 1.107 & 1.613 & 2.018 & 0.967 & 1.381 & 1.670
\end{tabular}

19 These estimates are based on specification (5), with Brazil's and China's Gini coefficients in 2004 of 0.60 and 0.35 , respectively, the latest year for which the survey provides data.

20 Because the SSA sample is much smaller than the global sample, the range is rather limited, especially when growth rates, rather than levels of the variables, are used, as in the current study. For example, Namibia's Gini coefficient was 0.74 in 1993, considerably larger than the sample maximum of 0.61; however, it is excluded from the present analysis due to the non-availability of other temporal data to calculate growth rates.

21 Based on specification (5), the maximum income-growth elasticity in SSA is about twice the minimum, with results for specification (6) exhibiting even larger ranges. 


\begin{tabular}{llllllll} 
Malawi* $_{\text {Mali }}$ & MWI & 1.256 & 1.877 & 2.387 & 1.503 & 2.293 & 3.028 \\
Mauritania & MLI & 1.238 & 1.846 & 2.344 & 1.268 & 1.879 & 2.364 \\
Mozambique & MRT & 1.255 & 1.877 & 2.387 & 1.453 & 2.204 & 2.882 \\
Namibia* & MOZ & 1.113 & 1.624 & 2.034 & 1.146 & 1.700 & 2.188 \\
Niger & NAM & 0.635 & 0.773 & 0.846 & 0.257 & 0.263 & 0.284 \\
Nigeria & NER & 1.175 & 1.734 & 2.187 & 1.210 & 1.783 & 2.231 \\
Rwanda & NGA & 1.211 & 1.799 & 2.278 & 0.967 & 1.359 & 1.569 \\
Senegal & RWA & 1.121 & 1.638 & 2.053 & 0.996 & 1.429 & 1.735 \\
Sierra Leone* & SEN & 1.216 & 1.808 & 2.290 & 1.429 & 2.174 & 2.869 \\
South Africa & SLE & 0.836 & 1.132 & 1.346 & 0.424 & 0.496 & 0.475 \\
Swaziland & ZAF & 0.926 & 1.291 & 1.569 & 0.922 & 1.360 & 1.809 \\
Uganda & SWZ & 1.051 & 1.513 & 1.878 & 0.962 & 1.391 & 1.741 \\
Tanzania & UGA & 1.137 & 1.666 & 2.093 & 0.612 & 0.737 & 0.582 \\
Zambia & TZA & 1.333 & 2.015 & 2.579 & 1.423 & 2.125 & 2.678 \\
Zimbabwe & ZMB & 1.049 & 1.511 & 1.876 & 0.741 & 0.995 & 1.090 \\
\hline
\end{tabular}

Notes: Countries marked with * were not in the original sample employed for the regression estimation due to the inability to generate growth rates from the single-year observations for these countries. The most recent data for each country are used for the computations reported here; see Table 2 for the formulas underlying the respective computations. Note that the differences in the estimates for specification (5) are due to (initial) inequality-level differences across countries, while those for specification (6) result additionally from income-level differences.

To provide a better sense of the differences of the income-growth elasticity among SSA countries, the estimates in Table 4 may be arranged into quintiles (see Table 2 of the online appendix). It is interesting to note that the compositions of the first and last quintiles are similar between specifications (5) and (6), suggesting that the level of inequality probably dominates the explanation of the categorization into the tails of the distribution. That is, a set of policy instruments that succeeds in reducing the level of inequality sufficiently could substantially raise the effectiveness of growth in reducing poverty. For instance, in the case of countries in the lowest quintile based on specification (5) (Botswana, Central African Republic, Lesotho, Namibia, Sierra Leone, and South Africa), on the one hand, the results suggest that particular attention should be paid to reducing inequality in order to enhance poverty reduction. For the countries in the highest quintile (Benin, Burkina Faso, Ethiopia, Mauritania, Malawi, and Tanzania), on the other hand, a greater focus on growth might be advisable.

An important result for policymaking, then, is that effective poverty reduction in SSA would require country-specific approaches based on especially the inequality attributes of countries. For example, with an income-growth elasticity of 1.4 associated with p0 for Ethiopia (Table 4, specification (5)), a 10 per cent rise in the growth rate of income should be translated to a reduction in the rate of poverty by 14 per cent. In the other extreme, however, similar growth acceleration would be expected to reduce the poverty rate by only 6 per cent in Namibia. Furthermore, as this relatively low poverty-reduction effectiveness of growth in Namibia is due to the country's higher level of inequality, the policy implication here is that greater attention should be paid to understanding the factors responsible for Namibia’s inequality profile. 


\section{Conclusion}

This study has explored the extent to which inequality influences the impact of growth on poverty reduction, based on a global sample of 1977-2004 unbalanced panel data for SSA and non-SSA countries. Several models are estimated with growths of the headcount, gap, and squared gap poverty ratios as respective dependent variables, and growths of the Gini and PPP-adjusted incomes as explanatory variables. For both SSA and non-SSA samples and for all three poverty measures - headcount, gap, and squared gap - the paper finds the impact of GDP growth on poverty reduction as a decreasing function of initial inequality. The study additionally observes that higher rates of increases in inequality tend to exacerbate poverty, with the magnitude of this effect rising with initial income. The income-growth elasticity, moreover, tends to increase with mean income relative to the poverty line.

The above estimated impacts are similar between the SSA and non-SSA samples with respect to direction, so that within either sample there are considerable disparities in terms of the responsiveness of poverty to changes in growth and inequality. Nevertheless, on average, the effects of both income and inequality variables are substantially less for SSA. This finding suggests that the marginal benefit in terms of poverty reduction in the SSA region would require larger reductions in inequality or accelerations in growth than elsewhere in the developing world.

Furthermore, the findings of the current study suggest that the growth impact is likely to differ by country in SSA, depending primarily on the inequality attributes of countries. For example, the poverty-reduction efficacy of a given rate of growth acceleration in Ethiopia would be more than twice that in Namibia, thanks to the much higher level of inequality in the latter country. Similarly, the degree of responsiveness of Botswana's poverty rate is estimated to be only slightly higher than that in Namibia, which might explain the minimal rate of poverty reduction in Botswana, with the headcount poverty rate for instance falling by only 5 percentage points in a decade, despite the tremendous growth in that country. 22 In contrast, in Ghana where the income-growth elasticity is about twice that of Namibia, the headcount poverty rate for example declined substantially, by about 10 percentage points within a decade, in spite of the relatively modest growth.23 Thus, understanding the inequality-generating characteristics of individual countries could help in designing most effective poverty-reducing strategies for this region of the world where the challenge seems so great.

\section{References}

Adams, R. H. (2004). 'Economic Growth, Inequality, and Poverty: Estimating the Growth Elasticity of Poverty’. World Development, 32 (12): 1989-2014.

Adelman, I. (1975). 'Development Economics: A Reassessment of Goals'. American Economic Review, 65 (2): 302-309.

22 Between 1985 and 1994, the headcount poverty rate in Botswana declined from 33.3 per cent to only 28.5 per cent (Source: present sample), despite the mean annual per capita GDP growth rate of nearly 5.0 per cent over the same period (World Bank 2007).

23 Ghana's headcount poverty rate fell from 46.5 per cent in 1987 to 36.2 per cent in 1998 (Source: present sample), and its annual per capita GDP growth rate averaged slightly less than 2.0 percentage points over the same period (World Bank 2007). 
Ali, A. A., and E. Thorbecke (2000). 'The State and Path of Poverty in Sub-Saharan Africa: Some Preliminary Results'. Journal of African Economies, 9, Supplement 1: 9-40.

Bruno, M., M. Ravallion, and L. Squire (1998). 'Equity and Growth in Developing Countries: Old and New Perspectives on Policy Issues’, in V. Tani and K.-Y. Chu (eds), Income Distribution and High Growth. Cambridge, MA: MIT Press.

Bourguignon, F. (2003). 'The Growth Elasticity of Poverty Reduction: Explaining Heterogeneity Across Countries and Time Periods', in T. S. Eicher and S. J. Turnovsky (eds), Inequality and Growth: Theory and Policy Implications. Cambridge, MA: MIT Press.

Chen, S., and M. Ravallion (1997). 'What Can the Survey Data Tell Us About Recent Changes in Distribution and Poverty?’. World Bank Economic Review, 11: 357-82.

Datt, G., and M. Ravallion (1992). 'Growth and Redistribution Components of Changes in Poverty: A Decomposition to Brazil and India in the 1980s'. Journal of Development Economics, 38 (2): 275-95.

Dollar, D., and A. Kraay (2002). 'Growth is Good for the Poor'. Journal of Economic Growth, 7 (3): 195-225.

Easterly, W. (2000). 'The Effect of IMF and World Bank Programs on Poverty'. Washington, DC: World Bank, mimeo.

Epaulard, A. (2003). 'Macroeconomic Performance and Poverty Reduction'. IMF Working Paper 03/72. Washington, DC: IMF.

Foster, J., J. Greer, and E. Thorbecke (1984). 'A Class of Decomposable Poverty Measures’. Econometrica, 52 (3): 761-66.

Fosu, A. K. (2001). 'Political Instability and Economic Growth in Developing Economies: Some Specification Empirics’. Economics Letters, 70 (2): 289-94.

Fosu, A. K. (2008). 'Inequality and the Growth-Poverty Nexus: Specification Empirics Using African Data'. Applied Economics Letters, 15 (7): 653-56.

Goldstein, J. S. (1985). 'Basic Human Needs: The Plateau Curve'. World Development, 13 (5): 595-609.

Hicks, N. L., and P. Streeten (1979). 'Indicators of Development: The Search for a Basic Needs Yardstick’. World Development 7 (6): 567-80.

Kakwani, N. (1993). 'Poverty and Economic Growth with Application to Cote d'Ivoire'. Review of Income and Wealth, 39 (2): 121-139.

Kalwij, A., and A. Verschoor (2007). 'Not by Growth Alone: The Role of the Distribution of Income in Regional Diversity in Poverty Reduction'. European Economic Review, 51 (4): 805-29.

Ram, R. (1985). 'The Role of Real Income Level and Income Distribution in Fulfilment of Basic Needs’. World Development, 13 (5): 589-94.

Ravallion, M. (1997). 'Can High-inequality Developing Countries Escape Absolute Poverty?’. Economics Letters, 56 (1): 51-57.

World Bank (2006a). Global Monitoring Report 2006. Washington, DC: World Bank

— (2006b). World Development Report 2006. Washington, DC: World Bank.

(2007). World Development Indicators Online 2007. Washington, DC: World Bank. 


\title{
Appendix
}

\author{
Appendix table \\ Inequality, growth, and poverty \\ Summary statistics, 1977-2004 unbalanced panel data \\ Sub-Saharan Africa (SSA) versus non-SSA
}

Appendix table A. Variables in levels

Non-SSA versus SSA (in brackets)

\begin{tabular}{ccccccccc}
\hline Variable & \multicolumn{2}{c}{ Mean } & \multicolumn{3}{c}{ Std. Dev. } & \multicolumn{2}{c}{ Min } & \multicolumn{2}{c}{ Max } \\
\hline p0 & 11.53 & {$[43.17]$} & 13.76 & {$[23.91]$} & 0.08 & {$[3.28]$} & 66.01 & {$[90.26]$} \\
p1 & 3.35 & {$[18.44]$} & 4.46 & {$[14.25]$} & 0.02 & {$[0.34]$} & 27.24 & {$[52.08]$} \\
p2 & 1.48 & {$[10.38]$} & 2.21 & {$[9.47]$} & 0.01 & {$[0.06]$} & 13.79 & {$[34.15]$} \\
Y & 167.07 & {$[64.86]$} & 92.98 & {$[39.73]$} & 35.24 & {$[19.03]$} & 440.02 & {$[205.98]$} \\
G & 0.42 & {$[0.45]$} & 0.11 & {$[0.07]$} & 0.17 & {$[0.30]$} & 0.63 & {$[0.63]$} \\
\hline
\end{tabular}

Appendix table B. Growth (log-differenced) rates and other variables Non-SSA versus SSA (in brackets)

\begin{tabular}{ccccccccc}
\hline Variable & \multicolumn{2}{c}{ Mean } & \multicolumn{2}{c}{ Std. Dev. } & \multicolumn{2}{c}{ Min } & \multicolumn{2}{c}{ Max } \\
\hline p0 & -0.126 & {$[-0.042]$} & 0.782 & {$[0.396]$} & -3.379 & {$[-0.760]$} & 4.632 & {$[1.480]$} \\
p1 & -0.153 & {$[-0.050]$} & 0.949 & {$[0.652]$} & -3.245 & {$[-1.325]$} & 5.037 & {$[2.255]$} \\
p2 & -0.172 & {$[-0.052]$} & 1.194 & {$[0.870]$} & -3.912 & {$[-1.904]$} & 4.396 & {$[2.803]$} \\
$\boldsymbol{Y}$ & 0.042 & {$[0.042]$} & 0.186 & {$[0.243]$} & -0.655 & {$[-0.860]$} & 0.638 & {$[0.710]$} \\
$\mathbf{G}$ & 0.008 & {$[0.007]$} & 0.091 & {$[0.154]$} & -0.320 & {$[-0.294]$} & 0.424 & {$[0.479]$} \\
$\boldsymbol{Y}^{\prime}$ & 161.408 & {$[62.665]$} & 91.262 & {$[41.580]$} & 25.400 & {$[18.470]$} & 440.020 & {$[224.59]$} \\
$\mathbf{G}^{\prime}$ & 0.417 & {$[0.448]$} & 0.104 & {$[0.082]$} & 0.171 & {$[0.289]$} & 0.634 & {$[0.607]$} \\
$\boldsymbol{Z I Y}$ & 0.288 & {$[0.677]$} & 0.203 & {$[0.636]$} & 0.074 & {$[0.159]$} & 0.929 & {$[1.720]$} \\
\hline
\end{tabular}

Notes:

p0 $=$ Headcount ratio (\% of population living in households with consumption or income per person below the poverty line); p1 = Poverty gap (mean distance below the poverty line as $\%$ of the poverty line); $22=$ Squared poverty gap (mean of squared distances below the poverty line as $\%$ of the poverty line); $\mathrm{Y}=$ Mean monthly per capita income/consumption expenditure from survey in 1993 PPP dollars; $G$ = Gini coefficient measuring the level of inequality; $\mathrm{YI}=$ Initial value of $\mathrm{Y} ; \mathrm{GI}=$ Initial value of the Gini coefficient; $\mathrm{Z} / \mathrm{Y}=$ Absolute poverty line in international PPP-adjusted 1993 dollars (US\$32.74) as a proportion of $\mathrm{Y} ; \mathrm{pj}=$ Log-difference of $\mathrm{Pj}(\mathrm{j}=0,1,2) ; \mathrm{y}=$ Log-difference of $\mathrm{Y} ; \mathrm{g}=$ Log-difference of the Gini coefficient.

The sample comprises the following SSA countries (with usable sample size of 51):

Botswana, Burkina Faso, Burundi, Cameroon, Côte d'Ivoire, Ethiopia, Gambia, Ghana, Kenya, Lesotho, Madagascar, Mali, Mauritania, Mozambique, Niger, Nigeria, Rwanda, Senegal, South Africa, Swaziland, Uganda, United Republic of Tanzania, Zambia, and Zimbabwe.

And the following non-SSA countries (with usable sample size of 302):

Albania, Algeria, Argentina, Armenia, Azerbaijan, Bangladesh, Bolivia, Brazil, Bulgaria, Cambodia, Chile, China, Colombia, Costa Rica, Dominican Republic, Ecuador, Egypt, El Salvador, Estonia, Georgia, Guatemala, Guyana, Honduras, India, Indonesia, Iran, Jamaica, Jordan, Kazakhstan, Kyrgyz Republic, Lao PDR, Latvia, Lithuania, Macedonia, Malaysia, Mexico, Moldova, Mongolia, Morocco, Nepal, Nicaragua, Pakistan, Panama, Paraguay, Peru, Philippines, Poland, Romania, Russian Federation, Sri Lanka, Tajikistan, Thailand, Trinidad and Tobago, Tunisia, Turkey, Turkmenistan, Ukraine, Uruguay, Uzbekistan, Venezuela, Vietnam, and Yemen.

Data source: http://iresearch.worldbank.org/PovcalNet/jsp/index.jsp 
Online appendix table 1

Inequality, Growth and Poverty: SSA versus non-SSA

Regression results (fixed country effects); dependent variables = pj $(j=0,1$, and 2 )

Online appendix table $1 \mathrm{~A}$, specification (5')

\begin{tabular}{|c|c|c|c|c|c|c|}
\hline & po & & $\mathrm{p} 1$ & & $\mathrm{p} 2$ & \\
\hline \multirow[t]{2}{*}{$y$} & $-2.959^{a}$ & $1.851^{a}$ & $-3.112^{a}$ & $1.508^{\mathrm{a}}$ & $-3.023^{a}$ & $1.047^{b}$ \\
\hline & $(-9.04)$ & (5.49) & $(-8.57)$ & (3.76) & $(-6.82)$ & $(2.03)$ \\
\hline \multirow[t]{2}{*}{$g$} & $5.371^{a}$ & $-4.323^{a}$ & $5.695^{a}$ & $-3.965^{a}$ & $5.299^{a}$ & $-3.141^{a}$ \\
\hline & $(6.74)$ & $(-5.29)$ & $(6.33)$ & $(-4.16)$ & $(4.99)$ & $(-2.72)$ \\
\hline$y G^{\prime}$ & -- & -- & -- & -- & -- & -- \\
\hline$g Y^{\prime}$ & -- & -- & -- & -- & -- & -- \\
\hline$y(Z / Y)$ & -- & -- & -- & -- & -- & -- \\
\hline Adj. $R^{2}$ & 0.48 & & 0.42 & & 0.26 & \\
\hline SEE & 0.53 & & 0.70 & & 0.99 & \\
\hline
\end{tabular}

Online appendix table 1B, specification (5)

\begin{tabular}{|c|c|c|c|c|c|c|}
\hline \multicolumn{3}{|c|}{$\mathrm{p} 0$} & \multicolumn{2}{|l|}{$\mathrm{p} 1$} & \multicolumn{2}{|l|}{$\mathrm{p} 2$} \\
\hline \multirow[t]{2}{*}{$y$} & $-5.803^{a}$ & $3.702^{b}$ & $-5.723^{a}$ & 2.066 & $-5.117^{a}$ & 0.143 \\
\hline & $(-3.60)$ & (2.16) & $(-3.38)$ & (1.03) & $(-2.92)$ & $(0.06)$ \\
\hline \multirow[t]{2}{*}{$g$} & $3.261^{\mathrm{a}}$ & $-3.099^{b}$ & $3.330^{b}$ & -3.202 & 2.877 & -2.734 \\
\hline & $(3.30)$ & $(-1.96)$ & $(2.28)$ & $(-1.15)$ & (1.31) & $(-0.68)$ \\
\hline \multirow[t]{2}{*}{$y G^{\prime}$} & $6.641^{b}$ & -4.474 & $6.082^{c}$ & -1.595 & 4.859 & 1.703 \\
\hline & $(2.06)$ & $(-1.30)$ & $(1.72)$ & $(-0.38)$ & (1.24) & (0.33) \\
\hline \multirow[t]{2}{*}{$g Y^{\prime}$} & $0.014^{b}$ & 0.001 & 0.016 & 0.012 & 0.016 & 0.018 \\
\hline & $(2.30)$ & $(0.04)$ & $(1.61)$ & $(0.25)$ & $(1.08)$ & $(0.27)$ \\
\hline$y(Z / Y)$ & -- & -- & -- & -- & -- & -- \\
\hline Adj. $R^{2}$ & 0.53 & & 0.44 & & 0.26 & \\
\hline SEE & 0.51 & & 0.68 & & 0.99 & \\
\hline
\end{tabular}


Online appendix table $1 \mathrm{C}$, specification (6)

\begin{tabular}{|c|c|c|c|c|c|c|}
\hline \multicolumn{3}{|c|}{$\mathrm{p} 0$} & \multicolumn{2}{|l|}{ p1 } & \multicolumn{2}{|l|}{ p2 } \\
\hline \multirow[t]{2}{*}{$y$} & $-9.596^{a}$ & $6.839^{b}$ & $-8.257^{a}$ & 3.603 & $-6.183^{b}$ & -0.374 \\
\hline & $(-3.33)$ & (2.24) & $(-2.75)$ & (1.02) & $(-2.13)$ & $(-0.10)$ \\
\hline \multirow[t]{2}{*}{$g$} & $5.729^{\mathrm{a}}$ & $-4.639^{a}$ & $5.958^{\mathrm{a}}$ & $-4.176^{a}$ & $5.442^{\mathrm{a}}$ & $-3.195^{a}$ \\
\hline & (8.12) & $(-6.44)$ & $(6.98)$ & $(-4.73)$ & $(5.20)$ & $(-2.90)$ \\
\hline \multirow[t]{2}{*}{$y G^{\prime}$} & $12.177^{b}$ & $-9.318^{b}$ & $10.057^{b}$ & -4.495 & 6.942 & 1.279 \\
\hline & $(2.48)$ & $(-1.82)$ & $(1.91)$ & $(-0.76)$ & (1.32) & $(0.20)$ \\
\hline$g Y^{\prime}$ & -- & -- & -- & -- & -- & -- \\
\hline \multirow[t]{2}{*}{$y(Z / Y)$} & $5.738^{b}$ & $-5.254^{b}$ & $3.438^{c}$ & -2.707 & 0.853 & 0.320 \\
\hline & (2.53) & $(-2.26)$ & (1.43) & $(-1.05)$ & $(0.33)$ & (0.11) \\
\hline Adj. $R^{2}$ & 0.54 & & 0.44 & & 0.26 & \\
\hline SEE & 0.50 & & 0.68 & & 0.99 & \\
\hline
\end{tabular}

Notes: $\quad{ }^{\mathrm{a}} 0.01$ significance (2-tailed); ${ }^{\mathrm{b}} 0.05$ significance; ${ }^{\mathrm{c}} 0.10$ significance

Estimation was conducted on the whole panel sample (size of 353) using 'differencesin-coefficients'. For each set of results, the first column represents non-SSA estimates while the next right-hand set (bolded) is the set of estimates for the SSA differential (that is, SSA less non-SSA), so that the sum of the two estimates for each row represents the SSA coefficient estimate for the respective explanatory variable. Under the null hypothesis that the coefficient parameter is the same for SSA and non-SSA, the right-hand estimates would not be significantly different from zero. $\mathrm{H}$ is the Hausman test statistic for choice between the Random Effects (RE) and Fixed Effects (FE) models, with the respective $p$-values in square brackets. The figures in parentheses are t-ratios based on robust standard errors; Adj. $\mathrm{R}^{2}$ and SEE are, respectively, the coefficient of determination and standard error of estimate. All other variables are as defined in the Appendix table of the text.

Online appendix table 2

Grouping of SSA countries by quintiles based on predicted income-growth elasticities

\begin{tabular}{|c|c|c|c|c|c|c|}
\hline & \multicolumn{3}{|c|}{ Specification (5) } & \multicolumn{3}{|c|}{ Specification (6) } \\
\hline & $\underline{\mathrm{p}}_{\underline{0}}$ & $\underline{\mathrm{p}}_{1}$ & $\underline{\mathrm{p}}_{2}$ & $\underline{\mathrm{P}}_{0}$ & $\underline{\mathrm{p}}_{1}$ & $\underline{\mathrm{P}}_{2}$ \\
\hline \multicolumn{7}{|l|}{$\mathrm{Q}_{1}$ lowest $20 \%$} \\
\hline & BWA & BWA & BWA & BWA & CAF & CAF \\
\hline & CAF & CAF & CAF & CAF & LSO & LSO \\
\hline & LSO & LSO & LSO & LSO & NAM & NAM \\
\hline & NAM & NAM & NAM & NAM & SLE & SLE \\
\hline & SLE & SLE & SLE & SLE & UGA & UGA \\
\hline & ZAF & ZAF & ZAF & UGA & ZMB & ZMB \\
\hline \multicolumn{7}{|l|}{$Q_{2} 20-40 \%$} \\
\hline & CIV & CIV & CIV & MDG & BWA & BWA \\
\hline & CPV & CPV & CPV & NER & MDG & MDG \\
\hline & GMB & GMB & GMB & RWA & NER & NER \\
\hline & SWZ & SWZ & SWZ & SWZ & RWA & RWA \\
\hline & ZMB & ZMB & ZMB & ZAF & SWZ & SWZ \\
\hline
\end{tabular}




\begin{tabular}{lllllll} 
Q $350-60 \%$ & ZWE & ZWE & ZWE & ZMB & ZAF & ZAF \\
& CMR & CMR & CMR & BDI & BDI & BDI \\
& MDG & MDG & MDG & CIV & CIV & CIV \\
& MOZ & MOZ & MOZ & CPV & CPV & GMB \\
& NER & NER & NER & GMB & GMB & MLI \\
& RWA & RWA & RWA & MOZ & MOZ & MOZ \\
Q4: 60-80\% & UGA & UGA & UGA & NGA & NGA & NGA \\
& & & & & & \\
& BDI & BDI & BDI & BFA & CMR & BFA \\
& GHA & GHA & GHA & CMR & GHA & CMR \\
& KEN & KEN & KEN & GHA & KEN & CPV \\
& MLI & MLI & MLI & KEN & MLI & GHA \\
& NGA & NGA & NGA & MLI & TZA & TZA \\
& SEN & SEN & SEN & ZWE & ZWE & ZWE \\
& & & & & \\
Q5: highest 20\% & BEN & BEN & BEN & BEN & BEN & BEN \\
& BFA & BFA & BFA & ETH & BFA & ETH \\
& ETH & ETH & ETH & MRT & ETH & KEN \\
& MRT & MRT & MRT & MWI & MRT & MRT \\
& MWI & MWI & MWI & SEN & MWI & MWI \\
& TZA & TZA & TZA & TZA & SEN & SEN \\
\hline
\end{tabular}

Notes: The categorization is based on the estimates provided in Table 4 of the text, which also contains definitions of the country acronyms. Country acronyms in each quintile are presented in alphabetical order. 